\title{
The Length Effect, the Repetition Frequency Effect and the Moment Effect of the Passage of the Product or of the Brand during a Television Spot on the Advertising Message (Tunisian Frame)
}

\author{
Tlich Imen \\ Quatitative Marketing at «'ISG »-Sousse /Tunisia
}

Correspondence should be addressed to: Tlich Imen; mabroukimene@yahoo.fr

Received 9 April 2012; Accepted 4 May 2012; Published 24 March 2013

Copyright (C) 2013 Tlich Imen. Distributed under Creative Commons CC-BY 3.0

\begin{abstract}
Nowadays, TV commercial spots efficiency became a major question which preoccupies marketing and commercial professionals. Experimentation is frequently used by researchers in order to model and assist marketing decisions.

Within this framework, this research aims to apply a « joint analysis » statistical study in order to measure the length and frequency of repetition of a publicity spot as well as the timing of a product or a brand apparition on the degree of memorization by viewers. Also, using logistical regression, we tried to locate the different components of attitude which have a direct impact on viewers' memorization.
\end{abstract}

For this, we have undertaken a survey on 288 individuals concerning eight Tunisian Publicity spots and covering 46 questions.

The joint analysis of the survey results show that the main determining factors on the publicity messages memorization are: (i) scarcity of repetition; (ii) long messages; (iii) and the timing of product or brand apparition during the spot.

On the other hand, the logistical regression of the survey results reveals that the evaluative attitude and the intention of purchase of buyers have a tight and close link to memorization.

Keywords: Experimentation, publicity, joint analysis, logistic regression, attitude, memorization.

Cite this Article as: Tlich Imen (2013), "The Length Effect, the Repetition Frequency Effect and the Moment Effect of the Passage of the Product or of the Brand during a Television Spot on the Advertising Message (Tunisian Frame)," Journal of Marketing Research \& Case Studies, Vol. 2013 (2013), Article ID 667225, DOI: $10.5171 / 2013.667225$ 


\section{Introduction}

Researches on the reception of the media and on the influence of communication move forward to such a speed as the scientific monitoring can be made only through an

external mediator working today directly in the sector of the scientific research. The practitioners arrange henceforth numerous theoretical models of decision-making support and particularly quantitative methods allowing them to obtain information to optimize the creation of messages, the elaboration of media plans, the persuasive speeches ... Even if the models are often multidisciplinary, a big part of the concepts and methods arise from the social psychology so quantitative methods (Courbet and Fourquet-courbet, 2005). On the other hand, the impact of communication actions may reveal two important questions: if commercials are really effective? How can we proceed to be able to measure their influences?

The answers are very complex as they are intimately related to psychology and to social psychology. In fact, it is difficult to estimate the efficiency of an advert, its contribution to the global demand and its influence on the distribution of the demand: does it stimulate the competition, rather, more credibly, does it favor the concentration of the demand on a small number of brands? The advertising executives consider that most of the messages are not perceived in the same way by the public, who can elaborate strategies of avoidance or resistance, even less memorized. The efficiency of an advertising communication depends not only on the message (which must be explicit and unambiguous) and of the support but also, worldwide, the general attitude of the individuals to the adverts and to the media. It is understood then the sense of "creativity" within advertising agencies, and the nature of the used media are at least very important so.

It is also necessary to create an interesting, transparent and a more concise message which can be memorized thanks to either its originality, shape, and or humour. In this research, and using the experimental method, we aim to elaborate and validate an evaluation technique of the broadcast spot efficiency. The researchers will try to evaluate the effect of the length of an advert; the repetition frequency and the transmission timing of a brand, on the efficiency of the spot broadcast. These will be assessed by the degree of memorization on behalf of the spectators which in turn can be evaluated through the relation which exists between the memorization and the various components of the attitude.

Today, in spite of the increasing various researches in a variety of disciplines (sociology, psychology, aesthetics, sociology, marketing, etc.), still many questions are yet to be answered as far as advertising is concerned. For that research in terms of conception and empirical results would allow better integration of experimental techniques in the strategies of communication and the marketing (Droesbeke and al, 1997).

Therefore this study comes to try to answer the following question: What are the main variables which influence the efficiency of a spot.

In fact, the literature on the efficiency of a spot articulates around three main determiners namely: the length of the message, its frequency of repetition and its contents. Among previous studies on the subject, we can quote the studies of (Bites and Gilson, 1985), (Fabien, 1986) and (Patzer, 1991) who show that the short messages are more efficient than the long messages. What contradicts with the results of the study of (Singh and Cole, 1993) which assert that the long emotional messages the frequency of repetition of which is low are the most memorized and consequently is the most effective.

While the study made by (Dumont, 2005) shows that the short spots are more efficient but more "fragile; because the short spots risk the increase of the advertising 
dimensions while the multiplication of messages decrease the efficiency of the short spots and increase that of the long spots. Several searches in marketing communication demonstrated that the simultaneous presence of both visual and verbal dimensions, called media investment, returns the more effective investment. Indeed, in that case the stimulus is more joined into the cognitive structure of the receiver, treated more in depth and consequently better memorized (Russel, 2002).

Considering the results of the previous works on the effect of the length, the contents and the frequency of repetition in an advertising context, the main objective of our research is to seize the effect of the length, the frequency of repetition and the moment of the passage of the product or the brand during the spot on the efficiency of the spot which will be evaluated through by the memorization of the slogan presented by this message.

\section{Study Framework}

This study will try to measure the efficiency of a spot in terms of its length and frequency and in terms of the moment of the brand passage. This will enable us to build the link between memorization and viewer attitude.

The spot efficiency evaluation passes through the measurement of the viewer memorization of this spot. Therefore, we elaborated a survey which allows the measurement of the degree of memorization as well as the attitude of the individuals with regard to the specific Tunisian spots. The questionnaire contains 46 questions, concerning 8 spots which were broadcasted during the month of Ramadan on the Tunisian national channel (example Al Wataniya I), It was observed that the majority of the Tunisian population watches the national channel during this month.

Eight spots were chosen in a very specified way, the criteria of choice being: the length, the frequency of repetition, and the passage of the product or brand during the spot passage: Eight spots were chosen based on different criteria.

The Criterion Length of a Spot: The various range of the spots spread during the month of Ramadan running on the national channel, were with various lengths, knowing that the lengths of a message confronts by its duration determined in seconds, we noticed that there are spots which lasted 25 seconds or more and spots which lasted 15 seconds or less; Based in this fact, we considered that those lasting 25 seconds or more and the short spots are those lasting 15 seconds or less.

For the variable length we associated the value 15s for the short spots and the value $25 \mathrm{~s}$ for the long spots

Indeed, eight chosen spots consist of four long messages and four short messages.

The Criterion Frequency of Repetition of a Spot: Knowing that the frequency of rehearsal of a spot during a day is in a tight connection with the budget of an advertising campaign, we indeed understand why the frequency of distribution of the spots varies from a brand to the other one.

Concerning the spots shown on the national channel during the month of Ramadan the frequencies of repetition are very varied, what led to us to resort to a classification of order of repetition. For the variable repetition we associated the value of the row of the frequency of repetition of the spot during the day. Therefore, the variable repetition takes the following values: $1 ; 2 ; 3$; $4 ; 5$.

The Criterion of the Moment of Passage of a Product or a Brand in a Spot: By observing the various spots shown on the national channel during the month of Ramadan, we noticed that ' there are spots which present the brand or the product at the end of the spot and the others present the brand or the product in the course of the spot; therefore it will be wise to compare 
between these two types of spots.

For the variable passage of the product or the brand, we are in the presence of a binary variable if a televised spot present the product or the brand in the course of the spot we associate to it the value 1 and if televised spot present the product or the brand at the end of the spot we associate to it the value 0 .

To better resolve this problem, we resorted to the techniques of experience plan, because the experiment consists in measuring the effects. Indeed Our search implies the presence of three explanatory variables: the length of the message, the moment of the passage of the product or the brand during the distribution of the spot and the frequency of repetition of this spot.

We indicate by:

$\mathrm{X} 1$ : the length of message this variable presents 2 modalities: short (15s) / Long (25s).

$\mathrm{X} 2$ : The moment of the passage this variable presents 2 modalities: Current (0) / has the end of (1).

X3: The frequency of repetition this variable presents 2 modalities: Frequent $(3.4,5)$ / Weak $(1,2)$.

It is about three variables in two modalities, the complete factorial plan of experience thus contains: $2^{3}=8$.

For variables to be explained, it is a question of:

$>$ The Variable "memorization": memorization of the slogan presented by the spot.

> The Variable "attitude": emotional attitude, evaluative attitude, attitude to the brand and the intention of purchase.

\section{The Joint Analysis}

Before presenting our results, we have to mention that, at the level of the joint analysis,

we modified the classic scope of this method. Indeed the joint analysis is a part of explanatory methods family and to connect a variable to be explained ordinal (generally the order rather consumers) in a set of qualitative explanatory variables (generally attributes of a product) Reibstein and al, (1988). Concerning our study, the specificity shows itself in following both levels:

* At the level of the nature of the dependent variables: we replaced the principle of the classification by the degree of memorization and we associated to the variable memorization an order of degree ( 4 if the filled referee the slogan correctly / 3 if the filled referee the slogan by a synonymic term / 2 if the filled referee the slogan by a false term / 1 if the referee does not fill the slogan).

* At the level of independent variables: we replaced the attributes of a product by the characteristics of a spot to know its length, its frequency of repetition and the moment of the passage (appearance) of the product or the brand during the message. Also, the nature of our independent variables is the same than that of the classic case of the joint analysis.

\section{Utility Importance Analysis}

The results of the joint analysis concern, first of all, the importance's of utility for the various attributes. We tried to calculate the frequencies of individuals who have either an importance of utility superior to $50 \%$, between $20 \%$ and $49 \%$ and lower than 20 $\%$, for every attribute. 


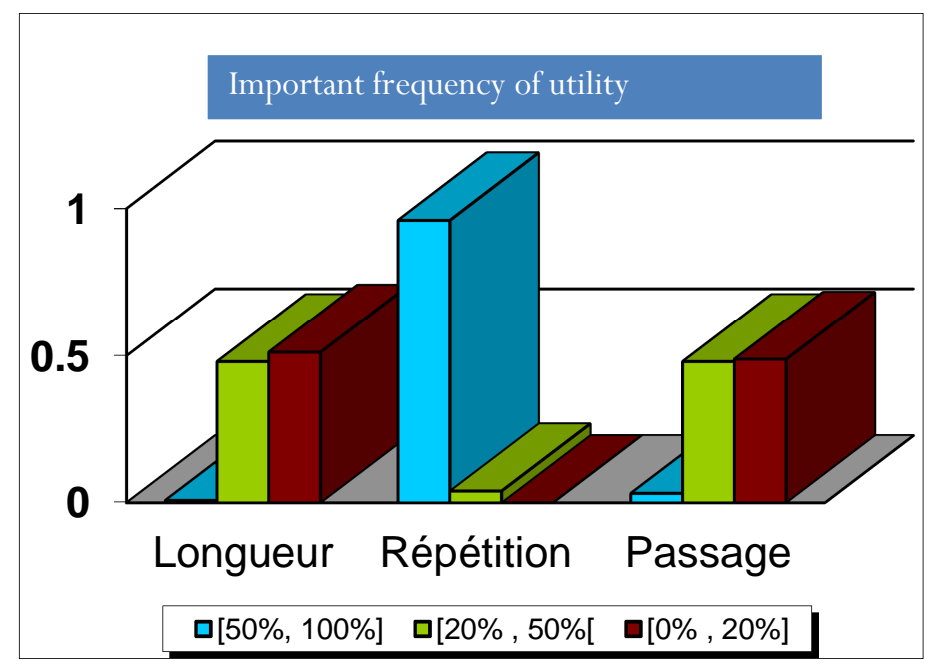

Fig.1. Important Frequency of Utility for Every Attribute

According to Fig.1, it is clear that the factor "repetition" has the most raised frequency in terms of utility superior to $50 \%$, which it means that the repetition has the highest effect memorization. Other factors, namely, length and moment of the passage of the product or the brand have a sharply less important effect on the spots memorization. Contrary to what is indicated in the study proposed by Singh and Cole (1993), stipulating that the length has a significant effect on the memorization for a low repetition for the emotional messages, we showed that the length for emotional messages has no important effect on the memorization, while it is the repetition which has a very determining effect on the memorization.

Table 1: Important Frequency of Utility for Every Attribute

\begin{tabular}{|c|c|c|c|}
\hline & \multicolumn{3}{|c|}{ Important frequency of utility } \\
\hline Importance of utility & Length & Repetition & Passage \\
\hline$[50 \%, 100 \%]$ & 0,008 & 0,96 & 0,032 \\
\hline$[20 \%, 50 \%[$ & 0,48 & 0,04 & 0,48 \\
\hline$[0 \%, 20 \%[$ & 0,512 & 0 & 0,488 \\
\hline
\end{tabular}

According to Table 1, it is clear that the repetition is the most important factor for the memorization of a spot. Around $96 \%$ of the population with a degree of utility superior or equal to $50 \%$ are affected by the repetition factor; $0.08 \%$ only (with a degree of utility superior or equal to $50 \%$ ) are affected by spot length; and $0.32 \%$ (with a degree of utility superior or equal to $50 \%$ ) were affected by the spot passage. 


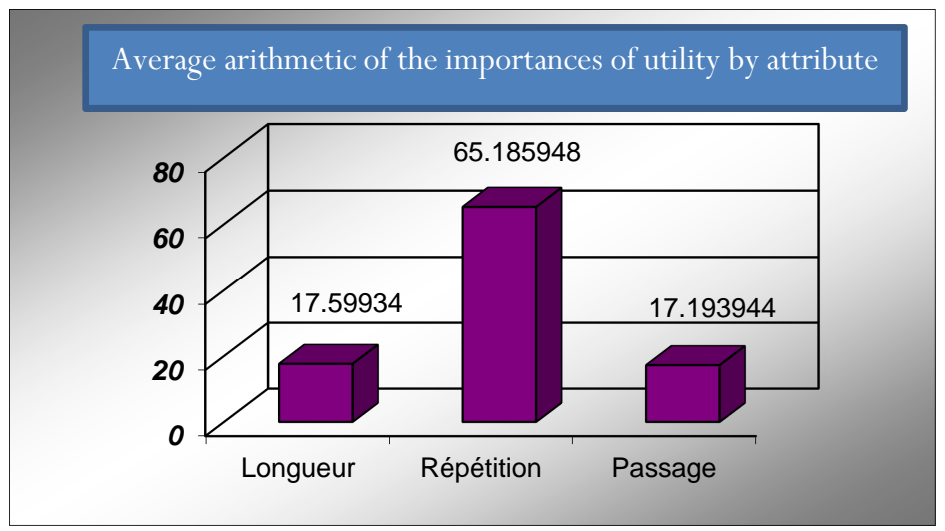

Fig 2. Average Arithmetic of the Importance of Utility by Attribute

From these results, we can assert that for our whole population, the importance of utility is $65,2 \%$ for the factor repetition and the rest is almost distributed in equality between the factor length and the factor passage (17.6\% and $17.2 \%$ ). Therefore the repetition has a determining effect on the memorization, while the length and the moment of the passage of the product or the brand have a less important effect on the memorization of the spot.

\section{Partial Utilities Analysis}

Analysis of the partial utilities allows us to visualize the effect of modalities on the various attributes. Indeed, we tried to see which of the modalities of each attribute has a real positive effect on memorization.

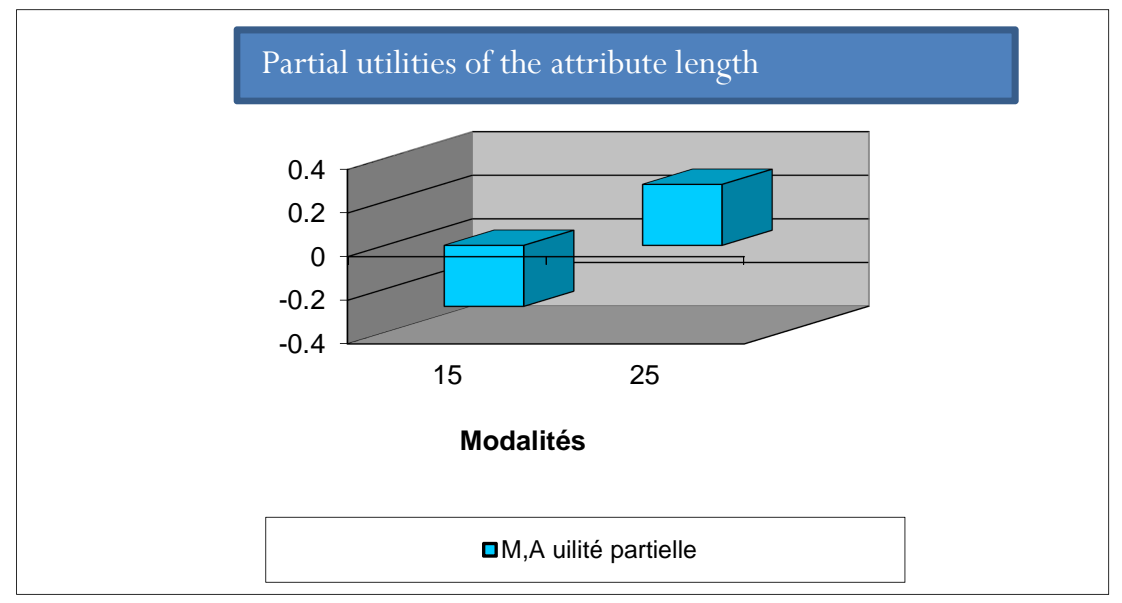

Fig3. Partial Utilities of the Attribute Length

By examining the partial utilities of each modality of the attribute length, we can conclude that only the long messages (25s) which have an effect on the memorization and not the short messages (15s). Thus to have an effect on the memorization, we have to choose long spots. 


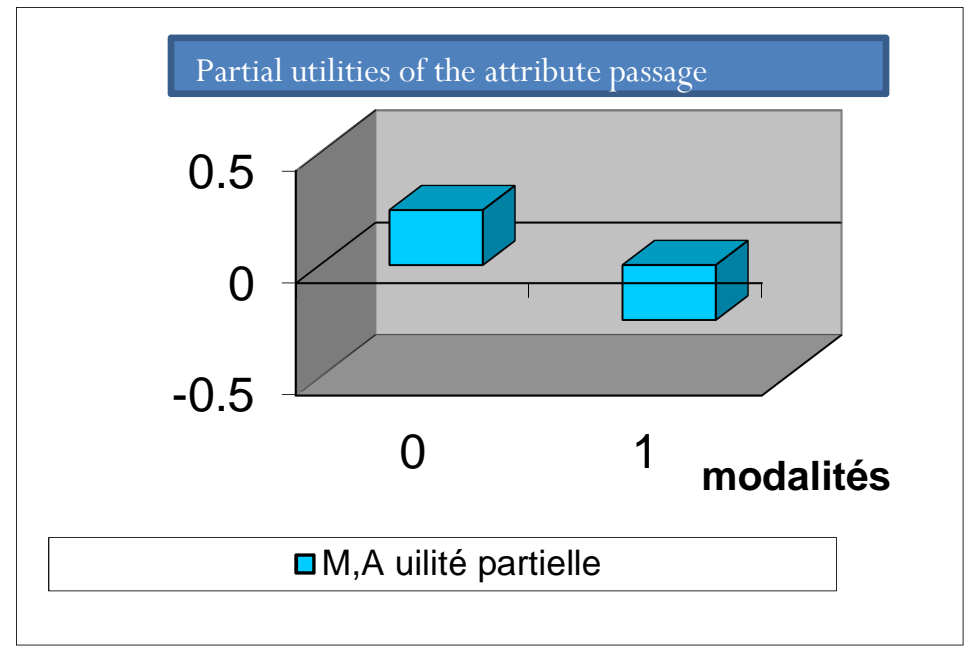

Fig4. Partial Utilities of the Attribute Passage

Concerning the attribute passage, it is only the televised advertising message showing the brand in the middle of the spot which have an effect on the memorization. While the televised adverts which show the product or the brand at the end, have no effect on viewer memorization.

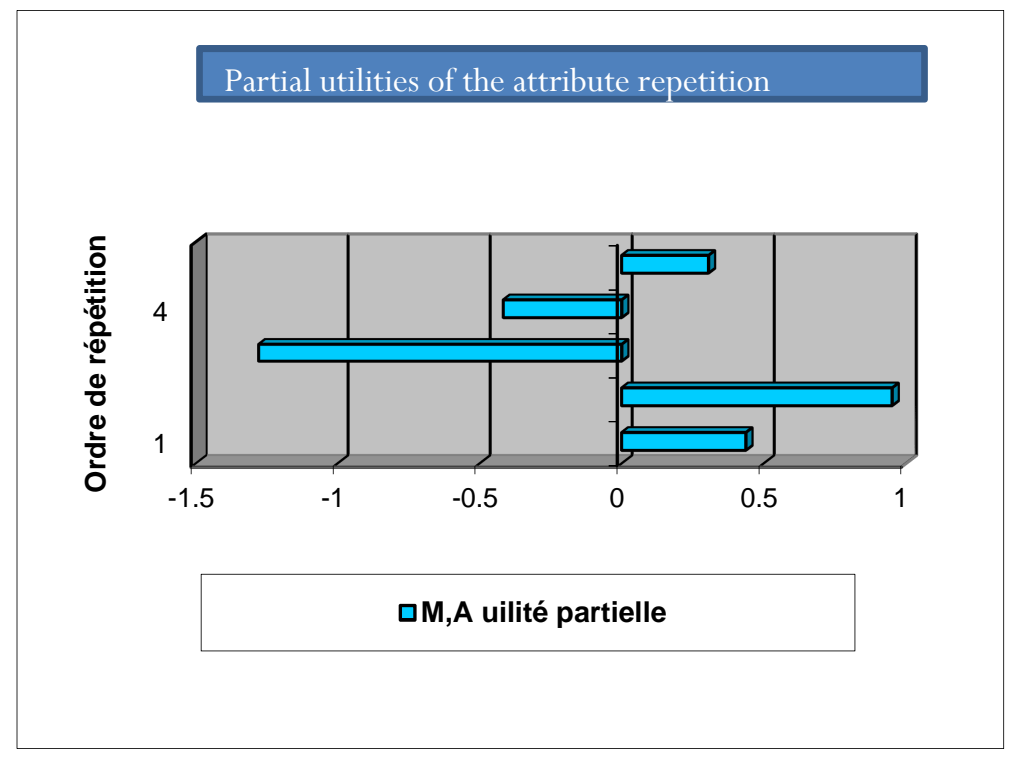

Fig5. Partial Utilities of the Attribute Repetition

Based on the above graphics and tables, we can see that the low repetition has a significant effect on the memorization, which means that the broadcast spot is well memorized if its frequency of repetition is low. In other words, as the frequency of repetition of the spot is lower, the memorization of the message will be higher. According to the results of the joint analysis, we can conclude that the low repetition is the 
most determining factor for memorization, while the length and the moment of passage of the product or the brand during the spot have an average effect on the memorization. Thus, according to our results, a long broadcast spot, showing the product or the brand during the spot and which repeats with a low frequency, is the one which has a very positive and important effect on its memorization.

\section{The Logistic Regression}

By applying the logistic regression we considered the variable memorization as being a binary variable and the variation of this variable is presented by a logistic model. If the respondent to the questionnaire remembers the slogan the variable takes the value 1 otherwise it takes the value 0 . Concerning the variable attitude which consists of the emotional attitude, the evaluative attitude, the attitude to the brand and the intention of purchase; we measured them through the calculation of the centered score: the centered score is the difference between the Score of each attitude and the average of the scores of this attitude. We looked by this application, to locate which one (s) among the components of the attitude is in narrow connection with the memorization. Therefore, we applied the logistic regression between the variable memorization and the various components of the attitude for every studied spot that is for every level of length, of frequency of repetition and of moment of passage of the product or the brand.

Therefore, we presented the results of the logistic regression for every studied spot, and we made the distinction between the messages howing the product or the brand during the spot and those howing the brand or the product at the end of the spot. We have to mention that the results supplied by the logistic regression are with regard to the behavior of non-memorization.

\section{The Televised Commercial Spots which Present the Product or the Brand during the Spot}

Table 2: La Rose Blanche: Long/Répétition Fréquente

\begin{tabular}{|c||c||c||c|}
\hline \multicolumn{1}{|c||}{ Variables } & Coefficient & Wald & p(signif) \\
\hline \hline Emotional attitude & -0.015 & 0.391 & 0.532 \\
\hline \hline Evaluative attitude & $-0.076^{*}$ & 9.408 & 0.002 \\
\hline \hline Attitude to the brand & $-0.080^{* *}$ & 4.962 & 0.026 \\
\hline Intention of purchase & 0.013 & 0.045 & 0.831 \\
\hline
\end{tabular}

* Significant at the beginning of $1 \%$

** Significant at the beginning of $5 \%$.

R2 of cox and snell: 0,179

$-2 \log$ - credibility: 178,730

According to the data supplied by the aforementioned picture, we notice that only the evaluative attitude and the attitude to the brand which have significant values (respectively 0.002 and 0.026 ) for the
Total number of respondents: 287

Number of referees for $M=0: 246$

Number of referees for $M=1: 4$

memorization. Indeed, when the evaluative attitude and the attitude to the brand are favorable thus the memorization of the spot will be made. 
Table 3: Cristal: Long/Répétition Faible

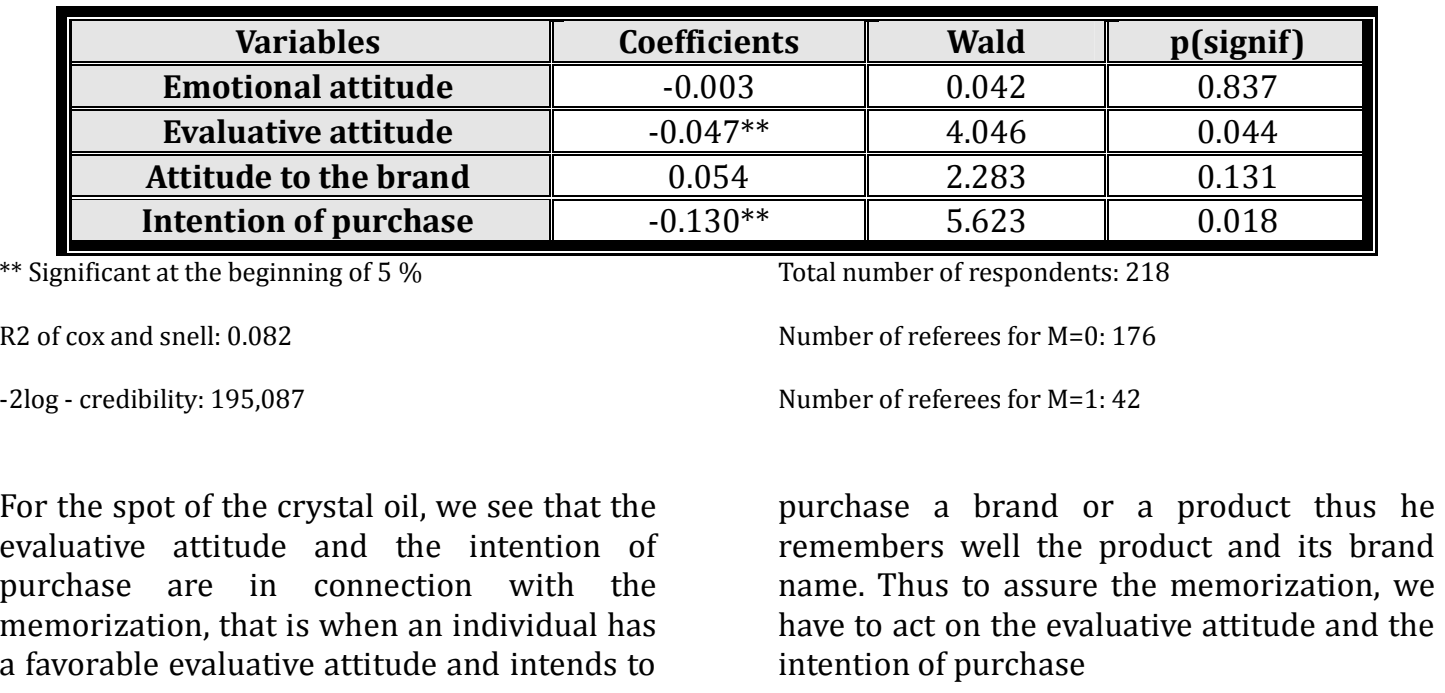

Table 4: Peaudouce: Courte/Répétition Fréquente

\begin{tabular}{|l||c||c||c|}
\hline Variables & Coefficients & Wald & p(signif) \\
\hline \hline Emotional attitude & -0.006 & 0.237 & 0.627 \\
\hline Evaluative attitude & -0.007 & 0.184 & 0.668 \\
\hline \hline Attitude to the brand & -0.018 & 0.472 & 0.492 \\
\hline \multicolumn{1}{|c||}{ Intention of purchase } & -0.021 & 0.313 & 0.576 \\
\hline
\end{tabular}

$\mathrm{R}^{2}$ of cox and snell: 0.033

-2log - credibility: 329,280

Total number of respondents: 275

In that case, we notice that none of the components of attitude has an effect on the
Number of referees for $\mathrm{M}=0: 84$

Number of referees for $\mathrm{M}=1: 191$

memorization. Absence of significativity of all the variables.

Table 5: UBCI: Courte / Répétition Faible

\begin{tabular}{|c|c|c|c|}
\hline Variables & Coefficients & Wald & p (signif) \\
\hline Emotional attitude & 0.026 & 2.748 & 0.097 \\
\hline Evaluative attitude & -0.018 & 0.415 & 0.519 \\
\hline Attitude to the brand & -0.014 & 0.098 & 0.754 \\
\hline Intention of purchase & -0.095 & 2.057 & 0.151 \\
\hline of cox and snell: 0,095 & \multicolumn{3}{|c|}{ Number of referees for $\mathrm{M}=0: 144$} \\
\hline -2log - credibility: 209,733 & \multicolumn{3}{|c|}{ Number of referees for $\mathrm{M}=1: 53$} \\
\hline
\end{tabular}

Total number of respondents: 197

For the spot UBCI, we see, also, that none of

significant effect on the memorization. 
The Televised Commercial Spots Which Present the Product or the Brand Has the End of the Spot

Table 6: L'ATB: Longue/Répétition Fréquente

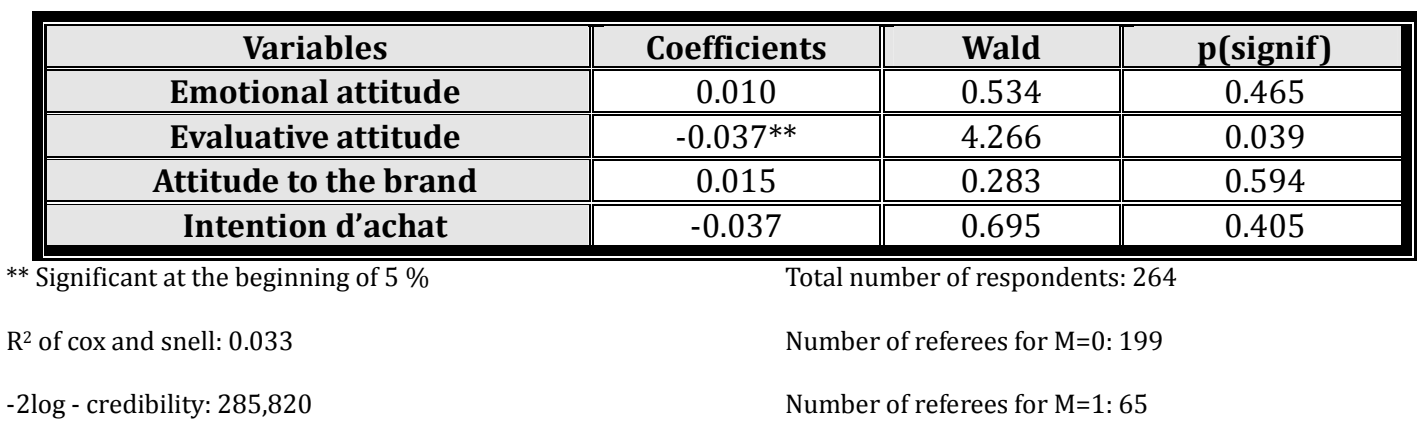

Based on the data shown in the previous table, we notice that only the evaluative attitude has a significant value. Thus for this case, only the evaluative attitude has an effect on memorization.

Table 7: Tunisie Télécom: Longue/Répétition Faible

\begin{tabular}{|c|c|c|c|}
\hline Variables & Coefficients & Wald & p(signif) \\
\hline Emotional attitude & -0.008 & 0.557 & 0.456 \\
\hline Evaluative attitude & $0.032 * *$ & 5.772 & 0.016 \\
\hline Attitude to the brand & -0.020 & 0.870 & 0.351 \\
\hline Intention d'achat & $-0.084^{* *}$ & 6.240 & 0.012 \\
\hline ** Significant at the beginning of $5 \%$ & \multicolumn{3}{|c|}{ Total number of referees: 285} \\
\hline R2 of cox and snell: 0.048 & \multicolumn{3}{|c|}{ Number of respondents for $M=1: 185$} \\
\hline -2log - credibility: 355,351 & \multicolumn{3}{|c|}{ Number of referees for $M=1: 100$} \\
\hline $\begin{array}{l}\text { For the spot Tunisia Telecoms } \\
\text { evaluative attitude and the in } \\
\text { purchase which present significar }\end{array}$ & \multicolumn{3}{|c|}{$\begin{array}{l}\text { shows once more that only these component } \\
\text { of the attitude which have an effect or } \\
\text { memorization. }\end{array}$} \\
\hline
\end{tabular}

Table 8: X-Plose: Courte/Répétition Fréquente

\begin{tabular}{|c|c|c|c|}
\hline Variables & Coefficients & Wald & p(signif) \\
\hline Emotional attitude & 0 & 0 & 0.990 \\
\hline Evaluative attitude & 0.023 & 2.352 & 0.125 \\
\hline Attitude to the brand & -0.011 & 0.176 & 0.675 \\
\hline Intention d'achat & $-0.086^{* *}$ & 4.478 & 0.034 \\
\hline the beginning of $5 \%$ & \multicolumn{3}{|c|}{ Total number of respondents: 228} \\
\hline ell: 0,041 & \multicolumn{3}{|c|}{ Number of referees for $M=0: 131$} \\
\hline$y: 301,360$ & \multicolumn{3}{|c|}{ Number of referees for $M=1: 97$} \\
\hline
\end{tabular}


For the above spot, only the intention of purchase presents a significant value. Thus in this case, the intention of purchase has a positive effect on the memorization.

Table 9: L’Epi D’or: Courte/Répétition Faible

\begin{tabular}{l||c||c||c|}
\hline \multicolumn{1}{|c||}{ Variables } & Coefficients & Wald & p(signif) \\
\hline \hline Emotional attitude & 0.002 & 0.019 & 0.891 \\
\hline Evaluative attitude & -0.016 & 0.864 & 0.353 \\
\hline Attitude to the brand & -0.023 & 0.928 & 0.335 \\
\hline Intention d'achat & -0.030 & 0.478 & 0.489 \\
\hline
\end{tabular}

Total number of respondents: 284

The results of the spot Golden ear, also show that none of the components of the attitude have a significant effect on memorization.

We notice according to the logistic regressions results, that in most the cases, only evaluative attitude and intention of purchase which present a positive connection with memorization. Thus we can assert that when an individual has a favorable evaluative attitude to a broadcast spot and an intention to purchase then he remembers the spot.

Indeed, we observe that there is a positive relation between memorization and the evaluative attitude. An intention to purchase is shown when the spot is long and $\backslash$ or of low repetition whenever is the moment of the appearance of the product or the brand during the spot.

This indicates that only the length of the message and its frequency of repetition which have an effect on the link attitude memorization.

\section{Conclusion, Limit and Prospect}

The advertising is any shape of interactive communication using a paying support set up for a transmitter. To reach its purpose, the advert has generally little time; it has simultaneously to catch the attention, to hold it, and to make its message pass. On this basis, an advert could be classified as a technique for manipulating of the consciousness.

In our empirical study, we tried to study the impact of the length of the spot, its frequency of repetition and the moment of the passage of the product or the brand in the course of a spot on the degree of memorization of the consumers. For that we had to refer to the experiments and to the application of the joint analysis in order to locate the components of the attitude (which are in narrow connection with the memorization) using the application of the logistic regression.

The results obtained, through the joint analysis, show that the low repetition of a broadcast spot is the most determining factor in the process of its memorization, while the length of the spot and the moment of the passage of the product or the brand during this spot have a less important effect on the memorization compared to the low repetition effect.

Based on results supplied by the logistic regression applied to every spot, we concluded that among the various components of the attitude, for the majority of the studied spots, only the evaluative attitude and the intention of purchase which present a connection with the memorization. We noticed that only the length of the message and $\backslash$ or its frequency of low 
repetition which have an effect on the link attitude-memorization.

In fact, this study could be led through experimental treatments and not by the distribution of questionnaires. So it may lead to more results concerning the effect of the length of a spot, its frequency of repetition and the moment of passage of the product or the brand during this spot on the attitude and its components. For that we recommend the application, of the logistic regression PLS (Partial Least Squares).

\section{References}

Courbet, D. \& Fourquet-courbet, M. P. (2005). "Modèles et Mesures de L'influence de la Communication: Nouvelles Perspectives Ouvertes par la Psychologie Sociale," Revue Internationale de Psychosociologie, vol XI, 25, p.171-195.

Droesbeke, J. J., Fine, J. \& Saporta, G. (1997). 'Plans D'expériences: Application à L'entreprise,' Paris, Edition Technip.

Droesbeke, J. J., Lejeune, M. \& Saporta, G. (2005). Modèles Statistiques pour Données Quantitatives, Société Française de Statistique, p.99.

Droulers, O. (2006). "Influence de L'âge sur la Mémorisation des Marques Présentées dans des Publicités à la Télévision," Revue Française du Marketing, N²08, p. 3-5.
Fabien, G.S. (1986). "15-Second Commercials: The Inevitable Evolution," Journal of Advertising Research, RC3-5.

Green, P. E. \& Srinivasan, V. (1978). "Conjoint Analysis in Consumer Research: Issues and Outlook," Journal of Marketing Research, vol 5.

Mord, M. S. \& Gilson, E. (1985). 'Shorter Units: Risk-Responsibility-Reward,' Journal of Advertising Research, 25, p.9-19.

Patzer, G. L. (1991). "Multiple Dimensions of Performance for 30-Second and 15-Second Commercials," Journal of Advertising Research, 31,p. 18-25.

Piquet, S. (2003). "Les Mutations du Marketing et de la Publicité," Revue Française du Marketing, $\mathrm{N}^{\circ} 192 / 193$, p. 2-3/5.

Reibstein, D., Dateson, J. E. C. \& Boulding, W. (1988). "Conjoint Analysis Reliability: Empirical Finding," Marketing Science, Vol 7,p. 271-286.

Russell, C. A. (2002). "Investigating the Effectiveness of Product Placement in Television Shows: The Role Modality and Plot Connection Congruence on Brand Memory and Attitude," Journal of Consumer Research, 29, p.306-318.

Singh, S. N. \& Cole, C. A. (1993). "The Effects of Length, Content, and Repetition on Television Commercial Effectiveness," Journal of Marketing Research, Vol XXX, p.91-104. 


\section{Appendix}

\section{Questionnaire}

On the occasion of the Master's dissertation, we elaborated the following questionnaire, and to have reliable results we urge you to fulfill it carefully; thank you for your collaboration.

Q1- Quote products or brands which drew your attention, by looking at the advertising spots of this month of Ramadan.

Q2- You would be generally ready to prefer or to change a product for the other one having looked at an advertising spot?

$$
\text { Yes ( ) No ( ) }
$$

The following questions are put about the advertising spot of pastas "La Rose Blanche" (the lady who prepares the dishes of the spaghetti within the store)

Q3- In your opinion, if you look at this advertising spot do you feel:

\begin{tabular}{|c|c|c|}
\hline Interested: & A lot & Not at all \\
\hline 11 & A lot & Not at all \\
\hline Irritated: & A lot & Not at all \\
\hline Amused: & A lot & Not at all \\
\hline & A lot & Not at all \\
\hline
\end{tabular}

Decentralized:

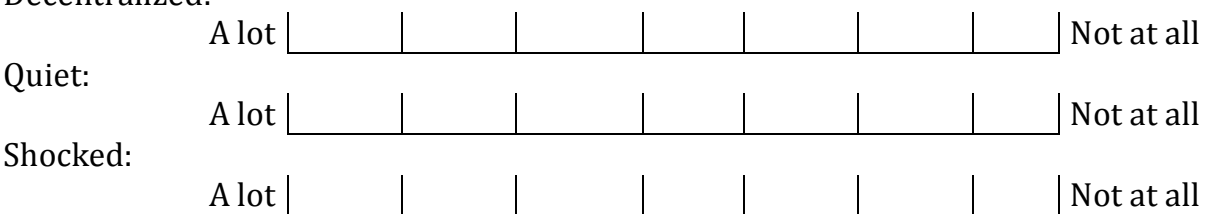

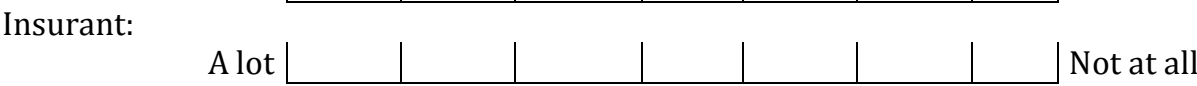

Impatient person:

Stimulated:

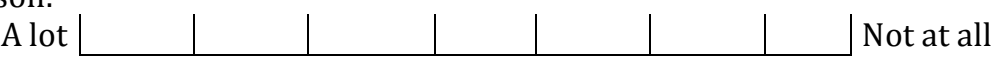

Perturbed:

\begin{tabular}{l|l|l|l|l|l|l|} 
Alot & & & & & & Not at all
\end{tabular}

\begin{tabular}{l|l|l|l|l|l|l|} 
Alot & & & & & & Not at all
\end{tabular}


Q4- What do you think of this advertising spot with regard to the others?

\begin{tabular}{|c|c|}
\hline Resembling & Different \\
\hline Pleasant & Unpleasant \\
\hline Refined & Vulgar \\
\hline Interesting & Not interesting \\
\hline Funny & Annoying \\
\hline Original & Ordinary \\
\hline Good & Bad \\
\hline Credible & Unbelieving \\
\hline Convincing & Not convincing \\
\hline
\end{tabular}

Clear and direct Mystery

Q5- What do you think of the brand "La Rose Blanche" presented by this advertising spot?

\begin{tabular}{|c|c|}
\hline I like very much & Not at all \\
\hline Useful & | Useless \\
\hline Important & Not important \\
\hline Valuable & | Worthless \\
\hline Pleasant & | Unpleasant \\
\hline Beneficiary & Overdrawn \\
\hline
\end{tabular}

Q6- Are you ready to buy pastas presented by this advertising spot?

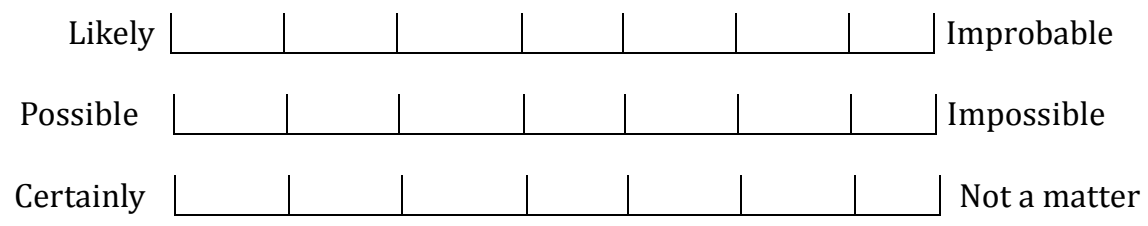

Q7- Complete the space in the following slogan:

$$
\text { الوردة البيضة وما }
$$


The same questions are put about the advertising spot of "Tunisie Télécoms" (people who have dinner around a table and who discuss between them)

Q8- In your opinion, if you look at this advertising spot do you feel:

\begin{tabular}{|c|c|c|}
\hline & A lot & Not at all \\
\hline Нарру: & A lot & Not at all \\
\hline 11 indeu. & A lot & Not at all \\
\hline & A lot & J Not at all \\
\hline & A lot & Not at all \\
\hline
\end{tabular}

Decentralized:

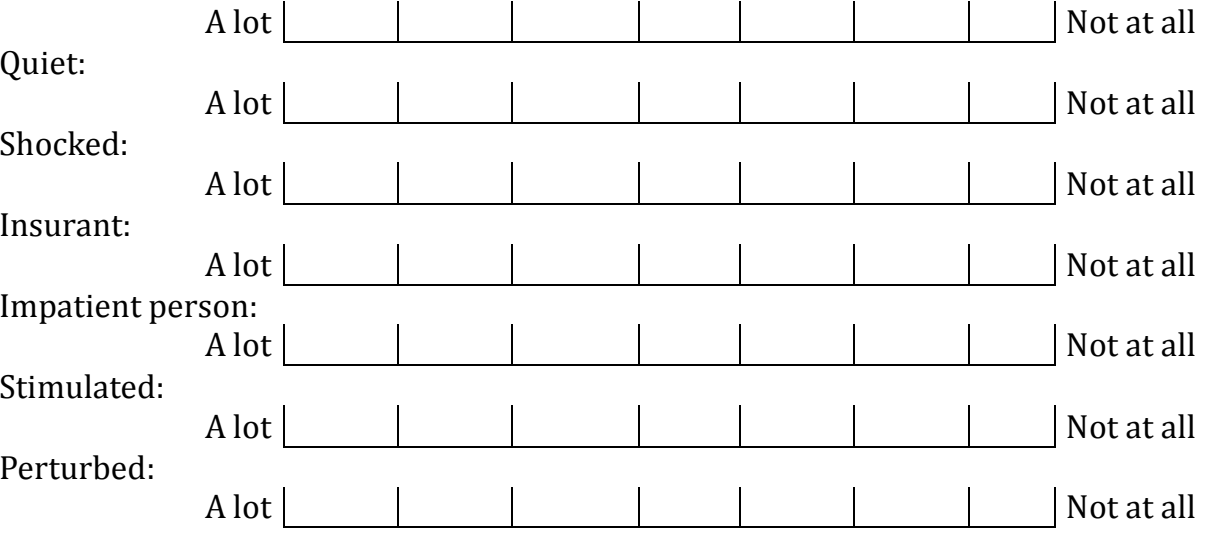

Q9- What do you think of this advertising spot with regard to the others?

\begin{tabular}{|c|c|}
\hline Resembling & Different \\
\hline Pleasant & Unpleasant \\
\hline Refined & |Vulgar \\
\hline Interesting & Not interesting \\
\hline Funny & Annoying \\
\hline Original & Ordinary \\
\hline Good L & Bad \\
\hline Credible & Unbelieving \\
\hline
\end{tabular}




\begin{tabular}{r|l|l|l|l|l|l|l|} 
Convincing & & & & & & & Not convincing \\
Clear and direct & & & & & & Mystery
\end{tabular}

Q10- What do you think of the brand "Tunisie Télécoms" presented by this advertising spot?

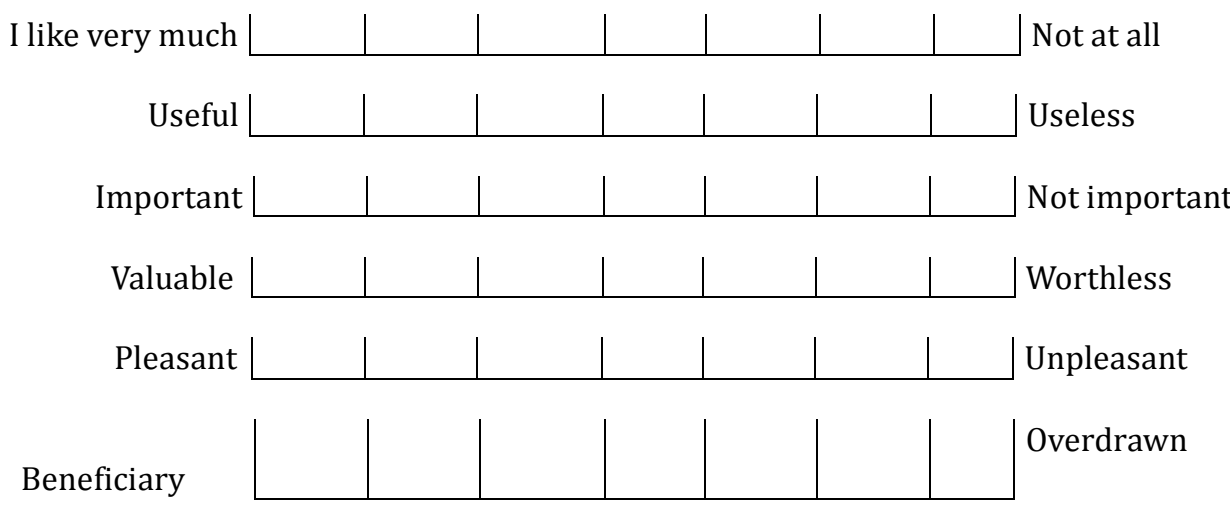

Q11- Are you ready to participate in the services of "Tunisie Télécoms"

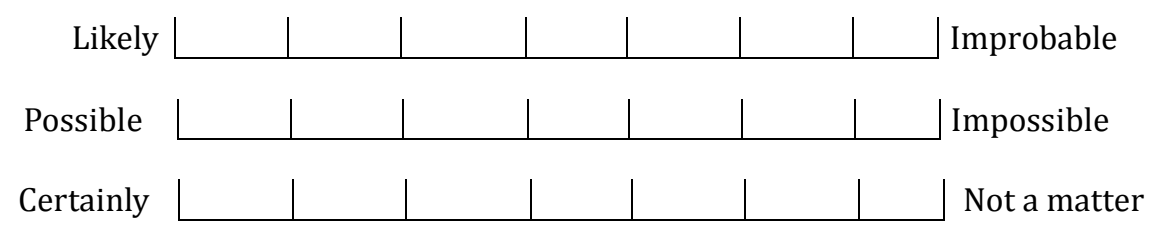

Q12- Complete the space in the following slogan:

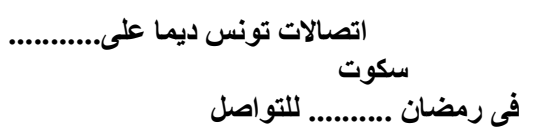

The same questions are put about the advertising spot of the bank "ATB" (horses and camels which run in the Sahara)

Q13- In your opinion, if you look at this advertising spot do you feel:

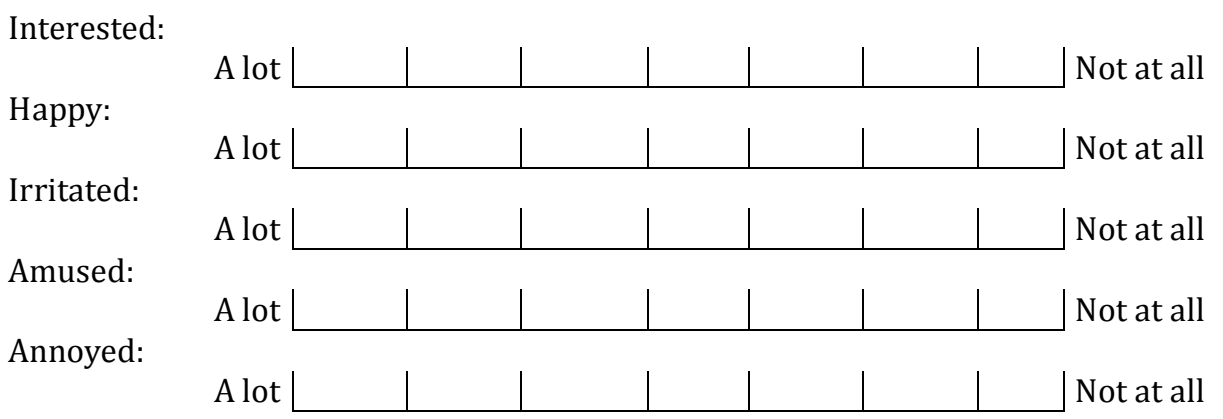


Decentralized:

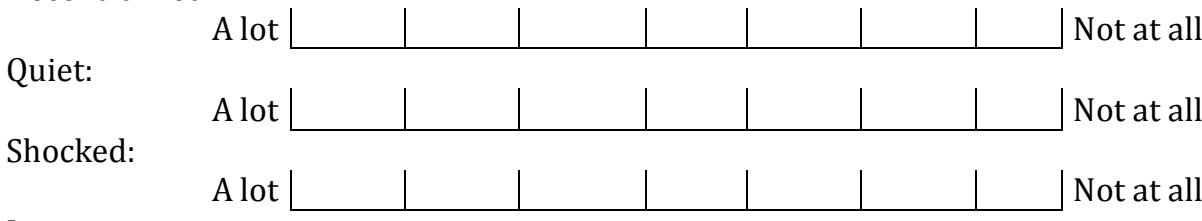

\begin{tabular}{|c|}
\hline A lot \\
\hline
\end{tabular}
Impatient person:

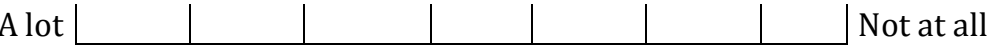

Stimulated:

Perturbed:

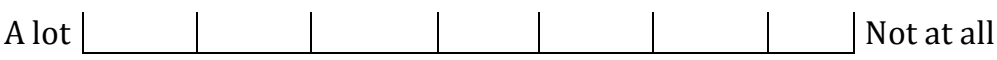

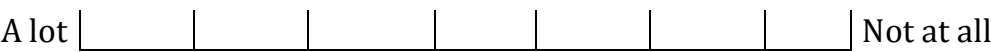

Q14- What do you think of this advertising spot with regard to the others?

\begin{tabular}{|c|c|}
\hline Resembling & ل Different \\
\hline Pleasant & | Unpleasant \\
\hline Refined & 」Vulgar \\
\hline Interesting & Not interesting \\
\hline Funny & | Annoying \\
\hline Original & 」Ordinary \\
\hline Good & 」 Bad \\
\hline Credible & | Unbelieving \\
\hline Convincing & | Not convincing \\
\hline$r$ and direct & | Mystery \\
\hline
\end{tabular}

Q15- What do you think of the "ATB" Bank presented by this advertising spot?

\begin{tabular}{|c|c|}
\hline I like very much & Not at all \\
\hline Useful & | Useless \\
\hline Important & Not important \\
\hline Valuable & Worthless \\
\hline Pleasant & Unpleasant \\
\hline & Overdrawn \\
\hline
\end{tabular}


Beneficiary

Q16- Are you ready to take advantage of the services of "ATB"

Likely
Possible
Certainly

Q17- Complete the space in the following slogan:

البنك العربي لتونس محترفون في

The same questions are put about the advertising spot of pastas "Epi d'or" (The old man who walks with his grandson in the wheatfield)

Q18- In your opinion, if you look at this advertising spot do you feel:

Interested:

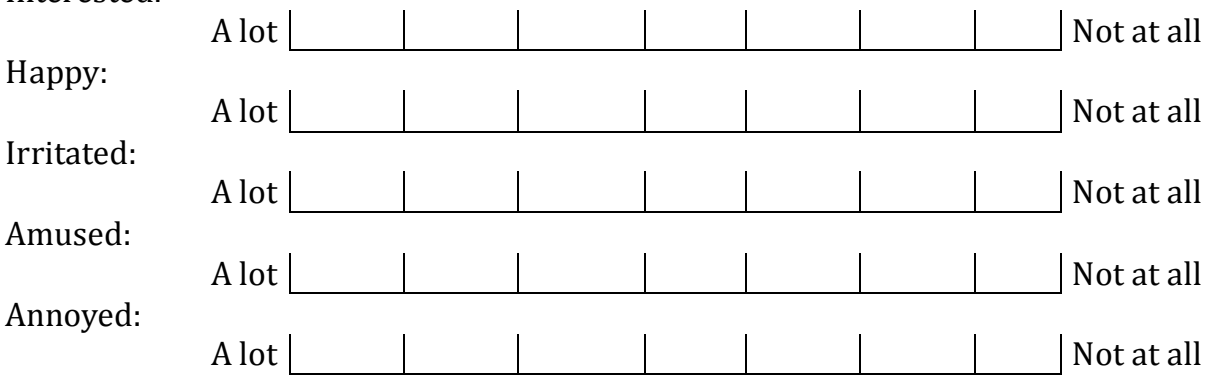

Decentralized:

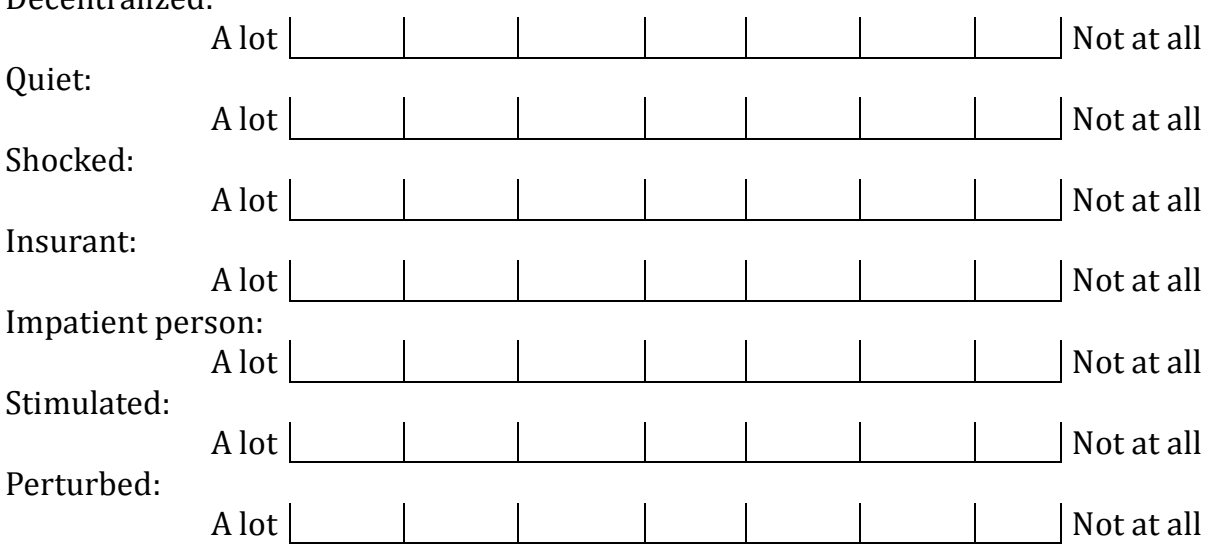

Q19- What do you think of this advertising spot with regard to the others?

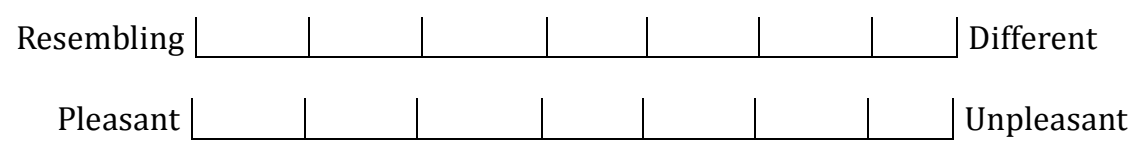




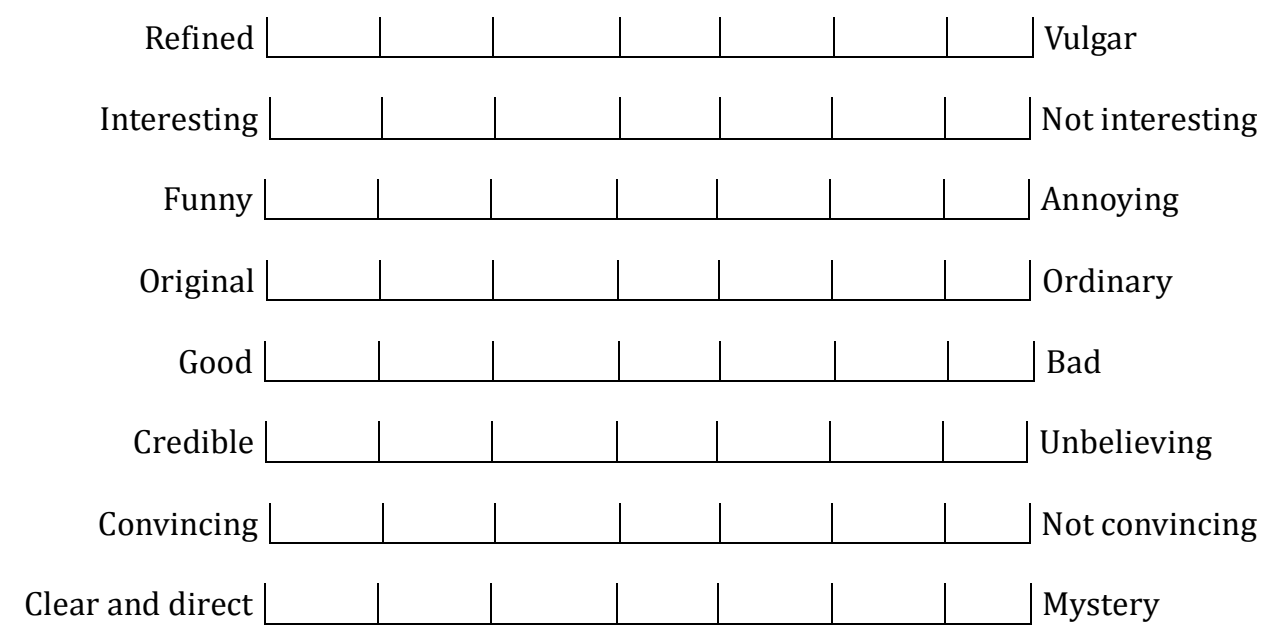

Q20- What do you think of the brand of "l'Epi d'or" presented by this advertising spot?

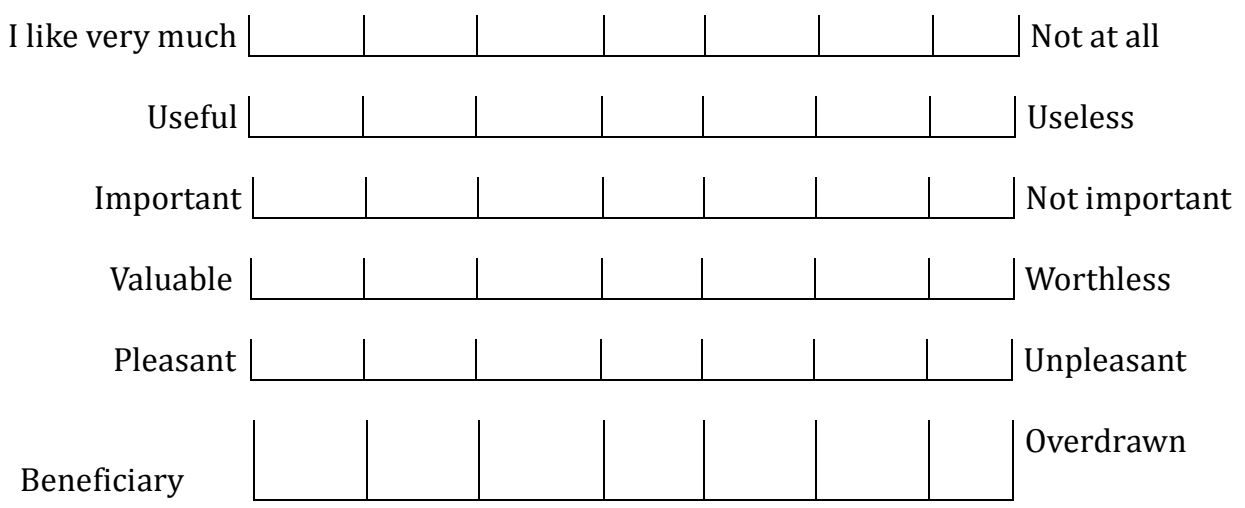

Q21- Are you ready to take advantage of the pastas of "Epi d'or"

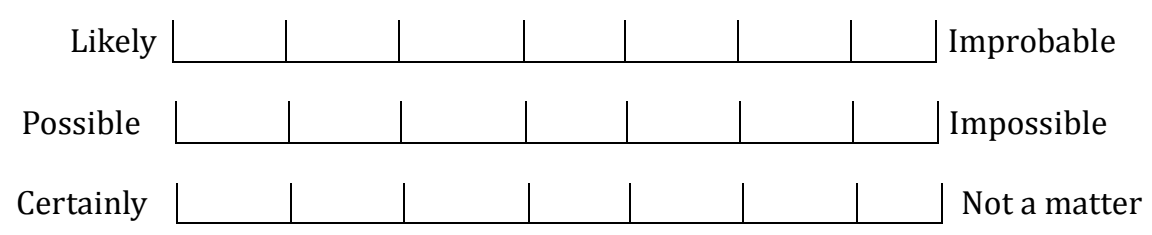

Q22- Complete the space in the following slogan:

Epi d'ormmm'..................

The same questions are put about the advertising spot of the chocolate "Xplose" (The sportsmen and the stuntmen who present hard acts to be made) 
Q23- In your opinion, if you look at this advertising spot do you feel:

Interested:

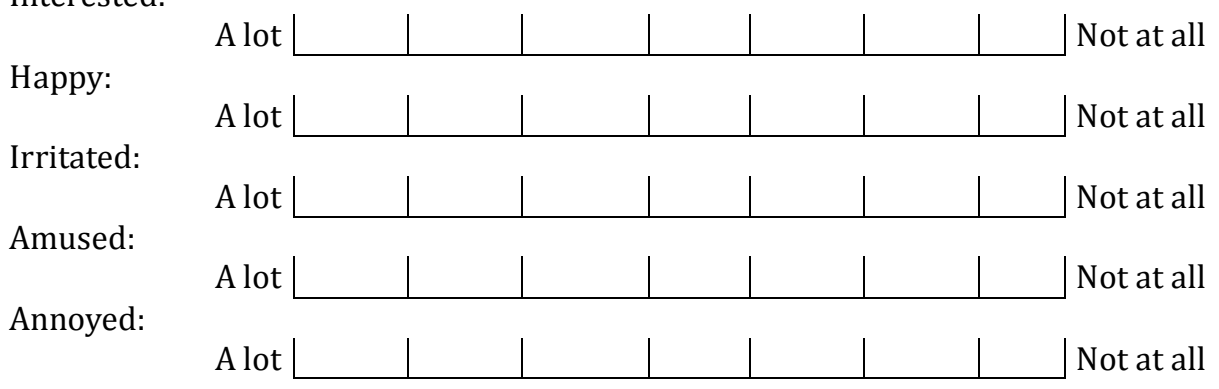

Decentralized:

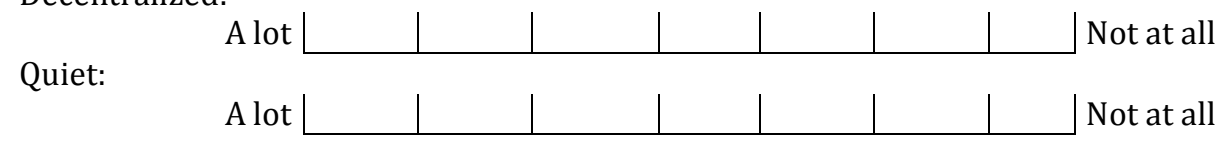

Shocked:

Insurant:

A lot \begin{tabular}{l|l|l|l|l|l|} 
Not at all \\
\hline
\end{tabular}

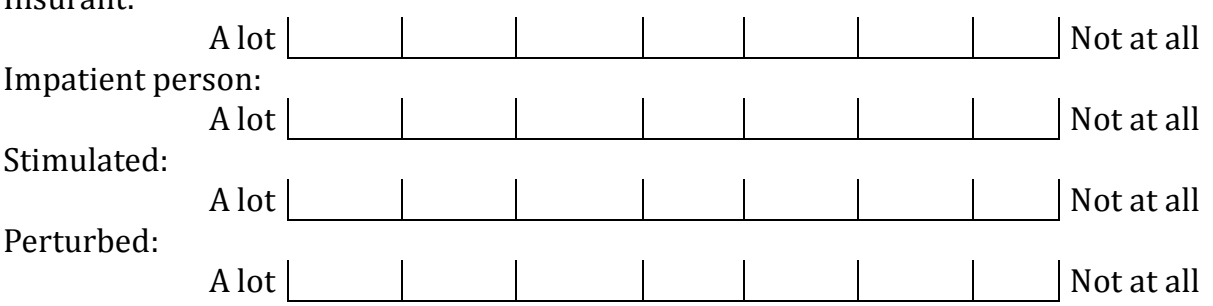

Q24- What do you think of this advertising spot with regard to the others?

\begin{tabular}{|c|c|}
\hline Resembling & Different \\
\hline Pleasant & Unpleasant \\
\hline Refined $L$ & |Vulgar \\
\hline Interesting & Not interesting \\
\hline Funny & Annoying \\
\hline Original & Ordinary \\
\hline Good L & Bad \\
\hline Credible & Unbelieving \\
\hline Convincing & Not convincing \\
\hline $\mathrm{r}$ and direct & Mystery \\
\hline
\end{tabular}


Q25- What do you think of the brand of "Xplose" presented by this advertising spot?

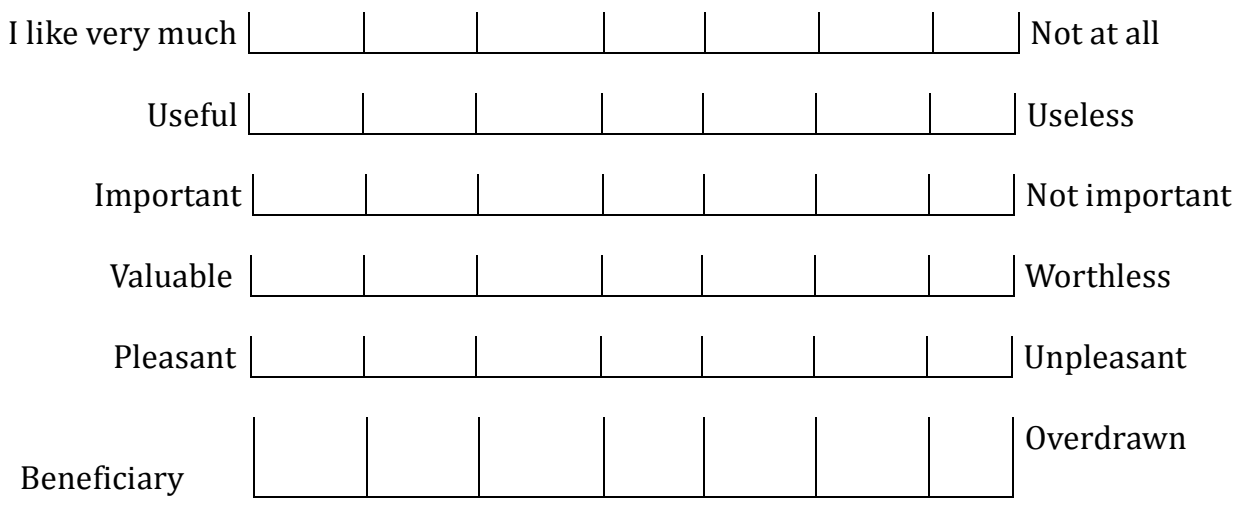

Q26- Are you ready to buy of the chocolate of "Xplose"

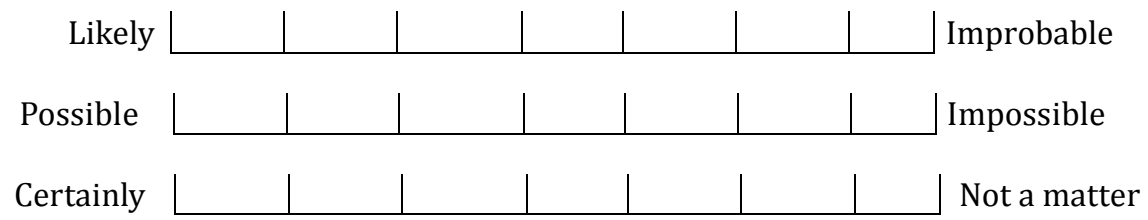

Q27- Complete the space in the following slogan:

تحدىXplose

The same questions are put about the spot of the oil "Cristal" (The bottle of the oil "Cristal" in big plan in the middle of the delicious Tunisian dishes)

Q28- In your opinion, if you look at this advertising spot do you feel:

Interested:

\begin{tabular}{|c|c|c|}
\hline (2) & A lot & Not at all \\
\hline RPy. & A lot & Not at all \\
\hline . & A lot & Not at all \\
\hline usea: & A lot & Not at all \\
\hline & A lot & Not at all \\
\hline
\end{tabular}

Decentralized:

Quiet:

Alot \begin{tabular}{l|l|l|l|l|l} 
Not at all
\end{tabular}

Shocked:

Alot \begin{tabular}{l|l|l|l|l|l|} 
Not at all
\end{tabular}

Alot \begin{tabular}{l|l|l|l|l|l|} 
Not at all \\
\hline
\end{tabular}


Insurant:

\begin{tabular}{l} 
Impatient person: \\
A lot \\
\hline
\end{tabular}

A lot \begin{tabular}{l|l|l|l|l|l|l} 
Not at all \\
\hline
\end{tabular}

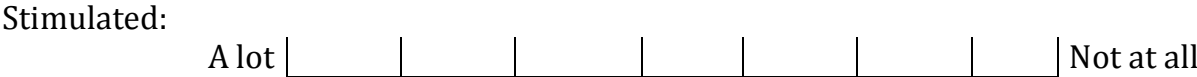

Perturbed:

Q29- What do you think of this advertising spot with regard to the others?

\begin{tabular}{|c|c|}
\hline Resembling & Different \\
\hline Pleasant & | Unpleasant \\
\hline Refined & |Vulgar \\
\hline Interesting & Not interesting \\
\hline Funny & Annoying \\
\hline Original & Ordinary \\
\hline Good & | Bad \\
\hline Credible & Unbelieving \\
\hline Convincing & Not convincing \\
\hline$r$ and direct & | Mystery \\
\hline
\end{tabular}

Q30- What do you think of the oil of "Cristal" presented by this advertising spot?

\begin{tabular}{|c|c|}
\hline I like very much & Not at all \\
\hline Useful & | Useless \\
\hline Important & Not important \\
\hline Valuable & | Worthless \\
\hline Pleasant & | Unpleasant \\
\hline Beneficiary & Overdrawn \\
\hline
\end{tabular}


Q31- Are you ready to buy of the oil of "Cristal"

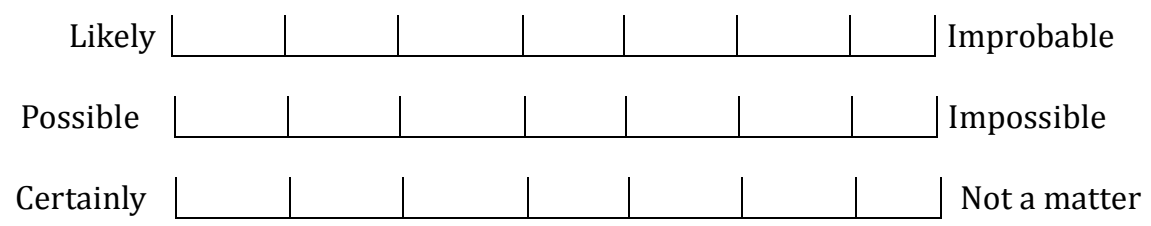

Q32- Complete the space in the following slogan:

بنة و ...............كل الاطباق

The same questions are put about the advertising spot of the bank "UBCI" (People who enter the bank wearing each a big poster which presents its project)

Q33- In your opinion, if you look at this advertising spot do you feel:

Interested:

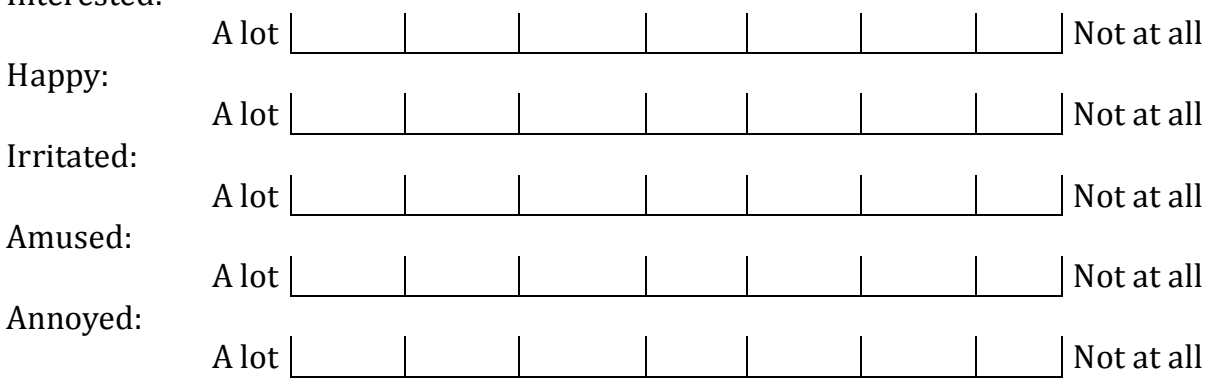

Decentralized:

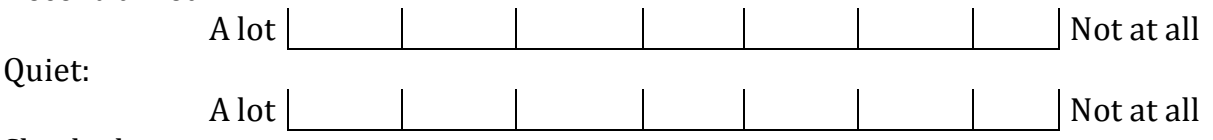

Shocked:

Insurant:

\begin{tabular}{l|l|l|l|l|l|l} 
A lot & & & & & & Not at all
\end{tabular}

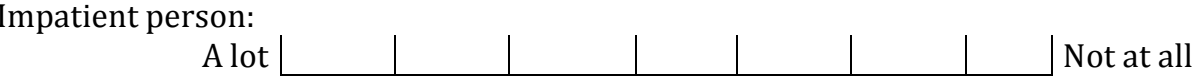

Stimulated:

Perturbed:

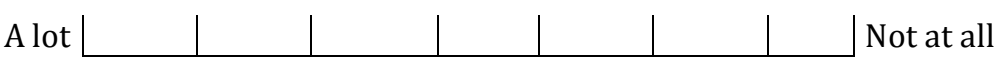

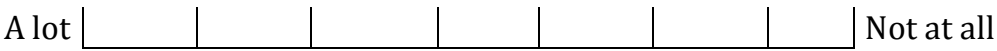

Q34- What do you think of this advertising spot with regard to the others?

Resembling $L$
Pleasant $L$




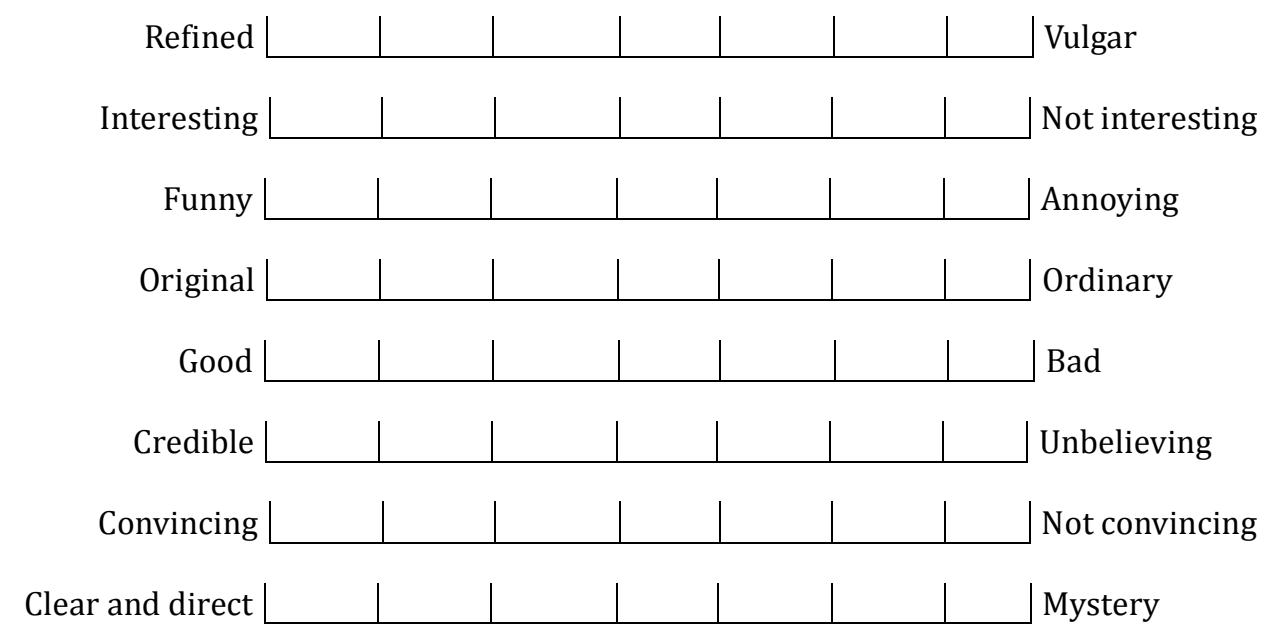

Q35- What do you think of the "UBCI" Bank presented by this advertising spot?

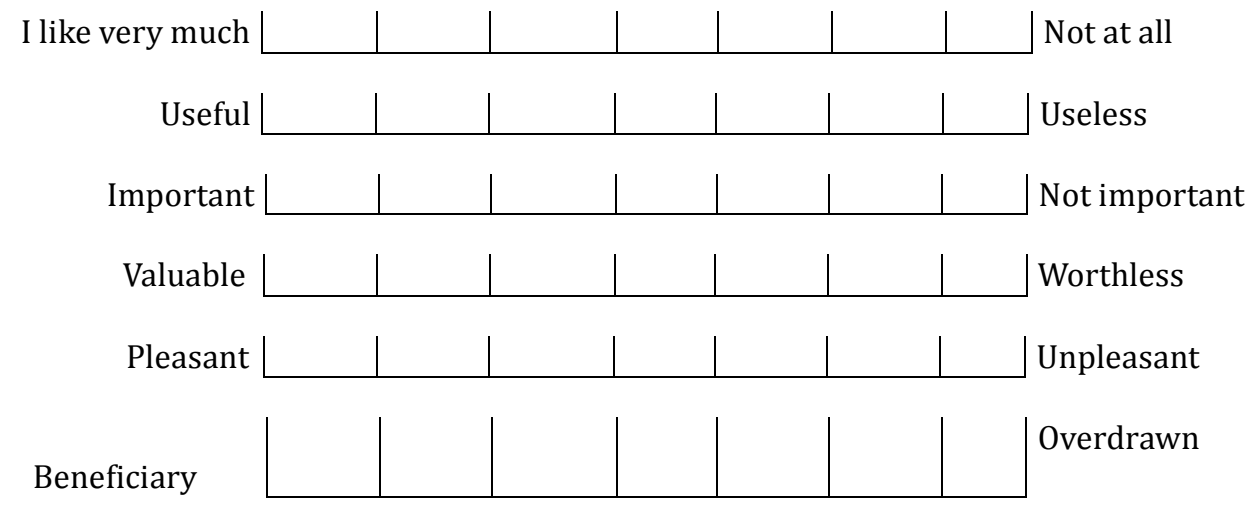

Q36- Are you ready to take advantage of the services of "UBCI"

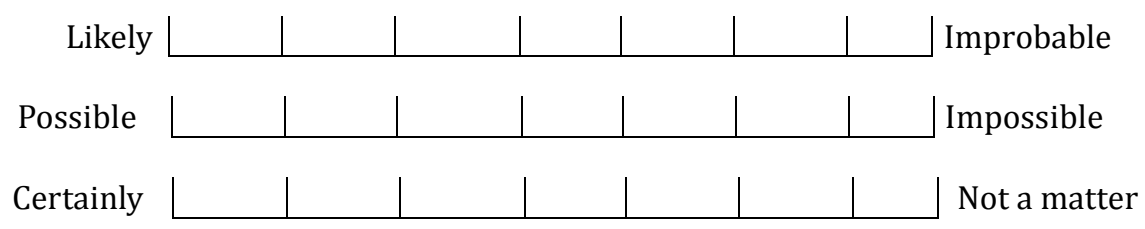

Q37- Complete the space in the following slogan:

$$
\text { UBCI }
$$

The same questions are put about the advertising spot of layer at baby "Peaudouce" (The baby who carries only his layer and who moves freely in a white space full of drawing made for hand) 
Q38- In your opinion, if you look at this advertising spot do you feel:

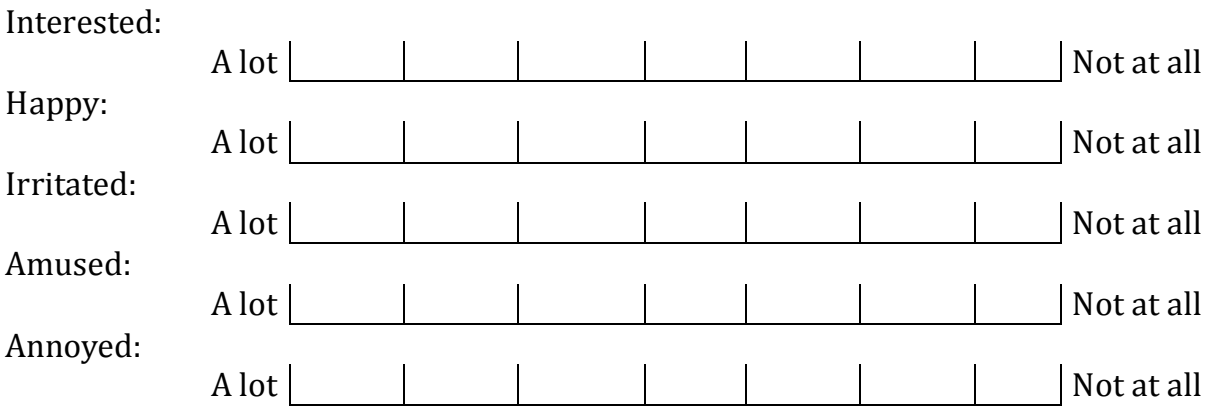

Decentralized:

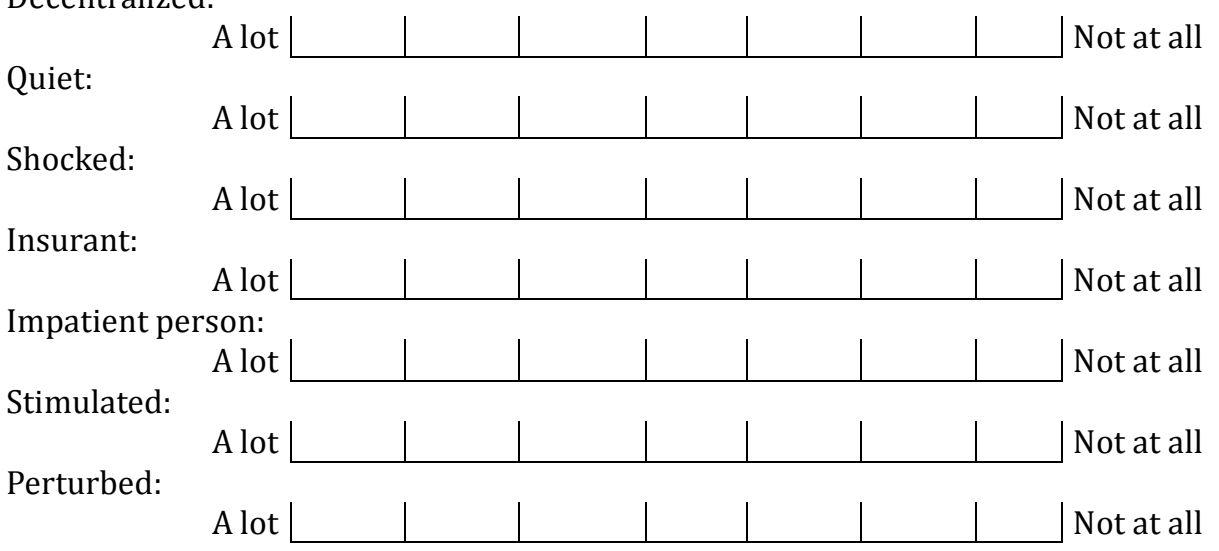

Q39- What do you think of this advertising spot with regard to the others?

\begin{tabular}{|c|c|}
\hline Resembling & | Different \\
\hline Pleasant $L$ & Unpleasant \\
\hline Refined & |Vulgar \\
\hline Interesting & Not interesting \\
\hline Funny & Annoying \\
\hline Original $L$ & Ordinary \\
\hline Good L & Bad \\
\hline Credible & Unbelieving \\
\hline Convincing & Not convincing \\
\hline and direct & Mystery \\
\hline
\end{tabular}


Q40- What do you think of the layer of "Peaudouce" presented by this advertising spot?

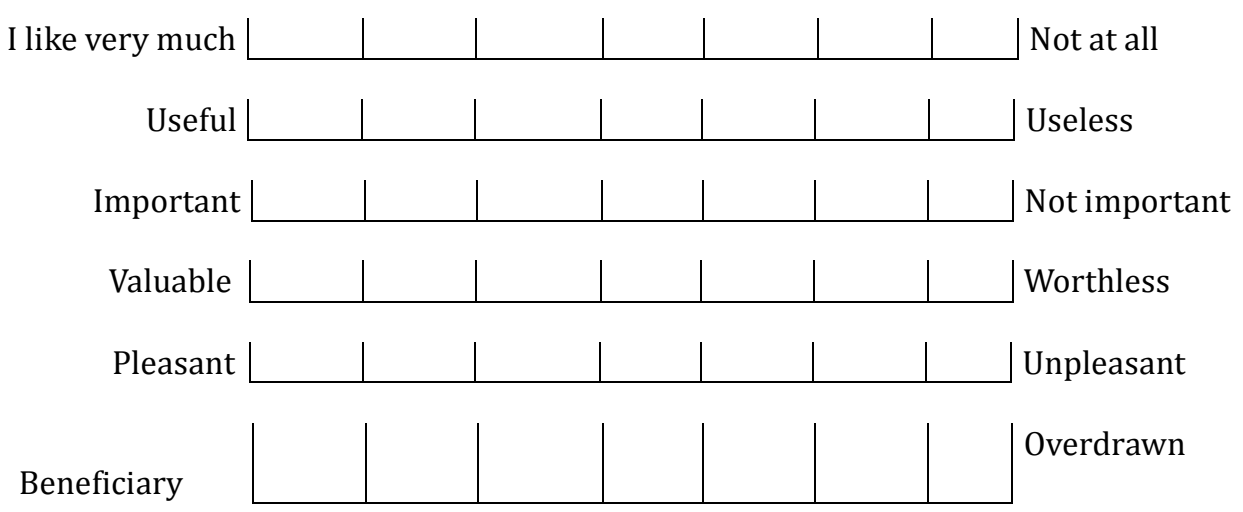

Q41- Are you ready to buy of the layer of "Peaudouce"

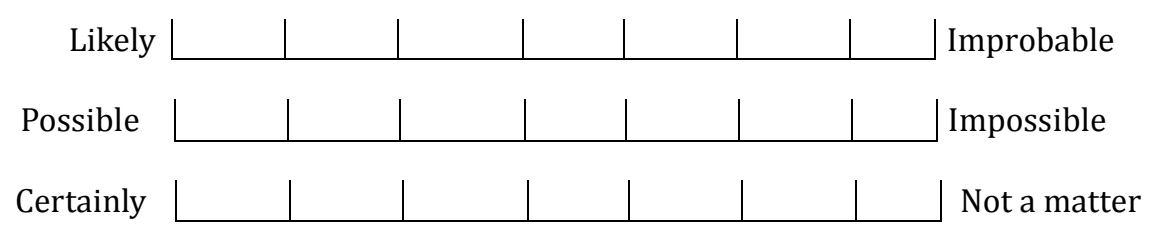

Q42- Complete the space in the following slogan:

يتربى في .............يتربى بيودوس

043- Are you a smoker?

Yes ( ) No ( )

Q44- Are you fascinated by the television? Yes ( ) No ( )

Q45-Sex:

$$
\text { Male ( ) }
$$

Female ( )

Q46) Age:

$\begin{array}{ll}\Rightarrow 15 & 20() \\ \Rightarrow 21 & 25() \\ \Rightarrow+25 & ()\end{array}$

Tlich Imen (2013), Journal of Marketing Research \& Case Studies, DOI: 10.5171/2013.667225 